\title{
CAN TRUST AND LOYALTY BE TRANSFERRED IN THE CASE OF A BRAND CHANGE?
}

\author{
Véronique Pauwels-Delassus, IESEG, France \\ Raluca Mogos Descotes, ESSCA, France
}

\begin{abstract}
Brand name substitutions have become a frequent phenomenon, and companies confronted with rebranding are often mentioned in the business press (Muzellec and Lambkin 2006). Several well known examples of brand name substitutions are Treets-M\&M's, Chambourcy-Nestlé and recently Thomson-Technicolor. Brand name substitution consists of changing the name of a product or service which is marketed by a company (Cegarra 1994). If the brand name substitutions are a strategic and current question for the managers, little academic research was carried out on this subject. In general, companies substitute "small" or "local' brands with stronger and frequently international brands. This decision is motivated in most of the cases by the increase of the profitability of brand portfolio. However, changing the brand name is a very risky decision, potentially nullifying many years of sustained investment in a brand name and can seriously damage or even destroy the brand equity (Muzellec and Lambkin 2006). Brand substitutions disturb the fundamental functional role of the brand, which relates to the recognition of the product on the shelf by the consumer, facilitating his choice of purchase (Kapferer 2004). When brand name substitutions occur, consumers might not recognise their usual product or doubt its quality, and thus stop buying it. Therefore, the most frequent negative consequence of brand change is brand loyalty loss, as a consequence of consumers' failure to recognise the product; this results in a decrease in market share.

Only two studies have addressed brand name substitution. Delassus (2005) studies the transfer of associations linked to the canned vegetable brand Marie Thumas which became Bonduelle in Belgium. Collange (2008) observes the evolution of French consumers' purchase intention across product categories (laundry detergent, shower gel, yoghurt and chocolate bars) focusing on four brand name substitutions. Both studies address the transfer of associations and purchase intentions, but they do not analyse how the brand relationship with the consumer is affected. The trust towards a brand can be seen as a stepping stone in the relationship the consumer builds with a brand, and it is also a strong predictor of the consumers' loyalty (Chaudhuri and Holbrook 2001; Delgado-Ballester and Manuera-Aleman 2005). For this reason, it seems to us of critical importance to identify the key influence factors of the transfer of brand trust and loyalty in the case of brand substitution. More specifically, in our study we focus on a brand change in the biscuit market. When Kraft bought the biscuits division LU of Danone in 2007, it lost all rights over the brand name Taillefine; Danone still uses the brand Taillefine for its milk-related products in France. Therefore, Kraft replaced the brand Taillefine with Belvita.
\end{abstract}

This research proposes and tests a model that aims to identify key determinants which could alleviate the loss of brand associations, trust and loyalty caused by brand name substitution on a convenience sample of 300 consumers. The empirical results related to the substitution of the biscuit brand Taillefine with Belvita reveal, that in order to effectively transfer loyalty, it is crucial that managers make sure they are able to transfer brand trust. Furthermore, trust transfer can be sustained if the most important associations of the brand are transferred. And finally, in order to transfer effectively the core associations of the substituted brand (1) consumers should have a high degree of acceptance of the replacement of the initial brand, (2) they should perceive the old and the new brand as similar, (3) they should not be too emotionally bound to the old brand and (4) the new brand should benefit from the presence of an umbrella brand. This research therefore has several managerial, theoretical and methodological implications.

References Available on Request. 